\title{
BEHAVIOR OF RUBBER HYDROCARBON IN A MOLECULAR STILL
}

\author{
By W. Harold Smith and Henry J. Wing ${ }^{1}$
}

\begin{abstract}
The values of the molecular weight of rubber reported in the literature vary from 600 to 350,000 and higher. If the vapor pressure were sufficiently increased, and maintained below the decomposition point of rubber, it seemed possible that the molecules, if small, might distil. To determine this, three distillations were attempted at $160^{\circ} \mathrm{C}$ for different periods, and with different temperatures at the condensing surface. In one experiment, which was conducted for about 100 hours, the condensing surface was chilled by liquid air. A thin transparent deposit, consisting of about $2 \mathrm{mg}$, appeared on the condensing surface. It was feebly extensible and did not recover completely when deformed. Its physical properties more nearly resembled rubber than those of other distillates. In a second experiment lasting 250 hours, solid carbon dioxide and acetone were used in the condenser, and in a third one, which was continuous during 140 days, the condensing medium was tap water at about $10^{\circ} \mathrm{C}$. It was difficult to remove oxygen from the specimens of rubber which were used. Consequently, the distillates in these experiments were oxidized, at least in part. The distillation products, one of which amounted to about $20 \mathrm{mg}$, were hard, transparent, and insoluble in ordinary solvents of rubber. In the third experiment the distillate amounted to about $20 \mathrm{mg}$ and showed an iodine number of 328 as compared with 370 for the original purified rubber, indicating that oxidation or cyclization or both may have taken place.
\end{abstract}

I. Introduction

II. Apparatus

III. Experimental results

IV. References

\section{INTRODUCTION}

Some investigators believe that rubber consists of associated molecules, and others accept Staudinger's view that long-chain molecules are formed by polymerization. Pummerer, Andriessen, and Gündel [1] ${ }^{2}$ have obtained a molecular weight as low as 600. Meyer and Mark [2] believe that it is approximately 5,000, although they calculated on the basis of osmotic pressures, values as high as 350,000 .

They, as well as Pummerer, consider that rubber is an associated colloid and that high molecular weights are caused by aggregates, sometimes called micelles. Staudinger [3], however, considers that the long-chain rubber molecule itself has a molecular weight of 200,000 or even 350,000 , and that products with lower values, which may be formed in rubber, result from degradation.

If the molecules are small it might be possible to distil them, if their vapor pressure could be sufficiently increased, but none would distil without decomposition if the molecules are very large. Because the vapor pressure of rubber below its decomposition temperature is low, it appeared of interest to attempt to distil the material in a

1 Present address, Milltown, N. J.

2 Figures in brackets indicate literature references at the end of this paper. 
molecular still. Paraffin wax and sugar, both substances of relatively high molecular weight, have been successfully distilled in this type of apparatus [4].

Subsequent to the work described in this paper, the molecular weight of sol rubber prepared at this Bureau was determined by $\mathrm{E}$. $\mathrm{O}$. Kraemer and J. D. Lansing [5] of E. I. du Pont de Nemours \& Co., Inc. They used the Svedberg method of sedimentation equilibrium in

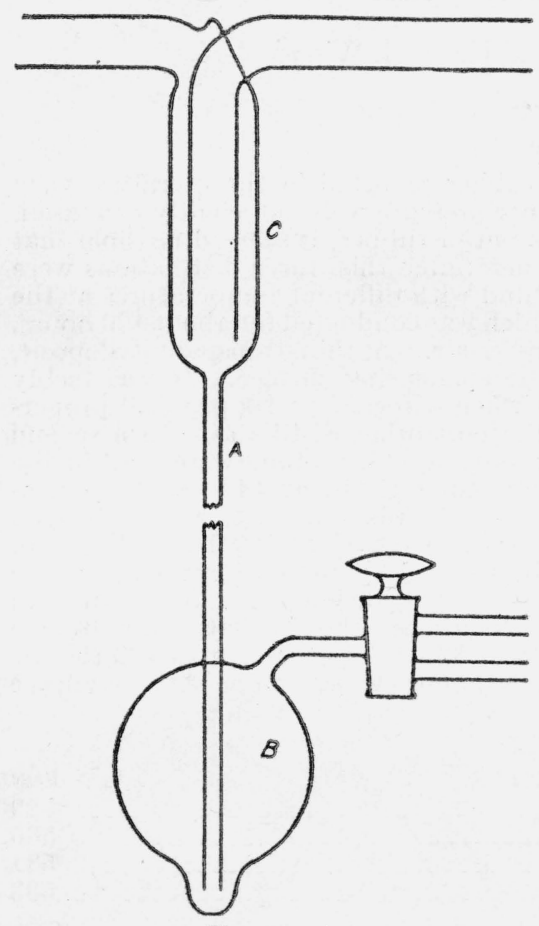

FIGURE 1. an ultracentrifuge with ethereal solutions of sol rubber. The temperature of the solutions during determinations was approximately $10^{\circ} \mathrm{C}$, and an average value of 460,000 was obtained. There was evidence of a mixture of molecular species.

\section{APPARATUS}

The stills, used in the attempt to distil rubber, consisted essentially of Pyrex Dewar flasks to which side-tubes were sealed that connected the flask to a mercury pump and its auxiliary equipment. The distance between the distilling and condensing glass surfaces was about $7 \mathrm{~mm}$, and the area of the distilling surface was approximately $60 \mathrm{~cm}^{2}$. The still was connected to a pumping system, equipped with a suitable trap to condense mercury vapor, and the apparatus was thoroughly evacuated before a distillation was attempted. When distillation extended over many weeks continuously, an automatic control was necessary, and between the still and the trap there was a device to isolate the high-vacuum system when the mercury pump or its condenser ceased to function. When either event occurred, a column of mercury automatically rose, effectively sealed the still, and maintained the low pressure within it. Simultaneously, a bell began to ring as a warning of trouble.

The equipment is illustrated in figures 1 to 4 . The mercury cutoff is shown in figure 1. The length of the tube must be properly adjusted so that the mercury in $B$ will rise to close the inner tube in $C$ when it responds to atmospheric pressure. In figure 2 , tube $B$ is an extension of its union with the mercury well of the cutoff. A Pyrex rod was welded to the stopper of stopcock $C$. In the closed position, the stopper was supported by a string over the pins, as shown in the diagram. The string ended in a loop which was held at $D$ by the catch at $C$. The catch, which resembles that on a common type of mousetrap, was opened when a current flowed through the electromagnet. The latter was operated by dry cells. When the catch was opened, the string was free to move, and was drawn away by a $200-\mathrm{g}$ weight. The capillary shown at $A$ in figure 2 prevented any surging of the mercury. At $E$ 
are shown the contact points of a relay which closed when the heater current to the pump was interrupted.

Figure 3 is a diagram of a switch, operated by water flowing to the condenser. The circuit to the electric hester of the pump was completed through tungsten contacts and mercury. The pressure of water passing through the tube, $A B$, to the condenser of the pump caused the mercury to rise and make contact. Two screw clamps at $A$ and $B$ regulated the speed and the head of the flow of water. In operation, the pressure head was so adjusted that the mercury stood well above the upper contact with water flowing, and well below when the flow of water stopped entirely. The position of the upper surface of the mercury was so adjusted that small fluctuations of the waterhead in the mains did not open the contact.

A wiring diagram is shown in figure 4 . The resistance, $R$, was sufficient to keep the relay, $E$, open, when the heater current was

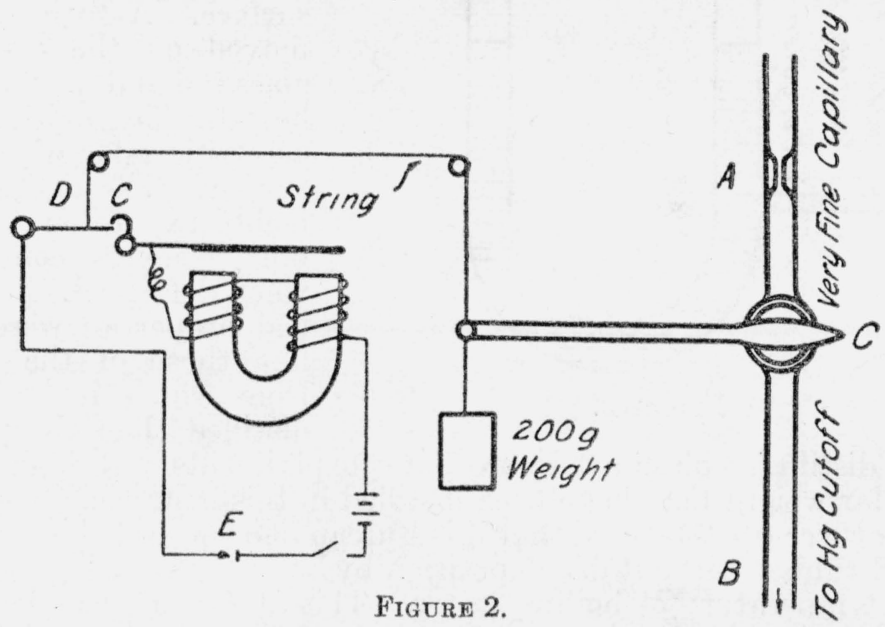

flowing. For a heater drawing about 2 amperes at 110 volts, 5 or 6 inches of No. 26 Nichrome wire was used. Since the relay contacts at $E$ were open when current was flowing through the relay magnet, any interruption of the current caused them to close, and completed the circuit to the trip of the mercury cutoff. If the heater current was stopped, the relay current also stopped, and in this case also the trip of the mercury cutoff responded.

\section{EXPERIMENTAL RESULTS}

Pure sol rubber hydrocarbon, prepared as described in a previous publication [6], was used in all of the experiments. Since the sol fraction is more mobile than the gel, it seemed probable that its molecules would become detached with greater ease. A solution of the rubber hydrocarbon in ether, saturated with nitrogen, was introduced and carefully spread over the distilling surface. The ether was removed at low pressure. The pressure maintained during distillation was too low to be measured by a McLeod gage, since the so-called "click" vacuum was obtained. Experiments with temperatures between $100^{\circ}$ and $150^{\circ} \mathrm{C}$ around the distilling surface produced no distillate. At $160^{\circ}$, after a few days, a faint deposit was observed $139015-39-4$ 
on the condenser by using a suitable lens, and in subsequent experiments this temperature was maintained by a heating coil.

Three distillations were performed for different periods and with different temperatures in the condenser. During the first experiment the condensing surface was chilled by liquid air. Distillation was conducted each day for about 8 hours for a total period of 100 hours.

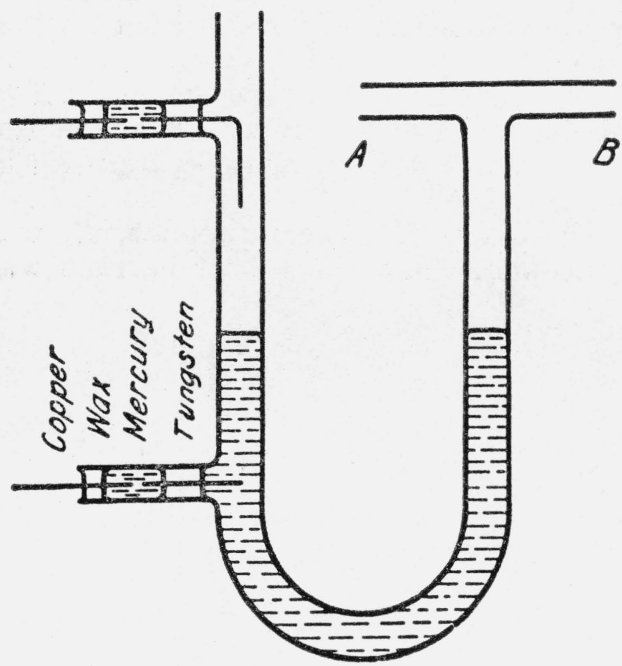

Figure 3.

The outer wall of the still was removed, and the condensing surface was washed with acetone. By using a hand lens, a very thin layer of transparent material, estimated to be not more than $2 \mathrm{mg}$, was visible on the condensing surface. A little was removed on the end of a glass rod and momentarily heated. There was a characteristic odor of burning rubber. The deposit was feebly extensible but did not recover completely when deformed. Its physical properties were more like those of the rubber from which it had been distilled than the properties of distillates obtained in any later experiments. Rubber of low molecular weight may have been distilled in this instance.

An earlier note [7] stated that this Bureau had succeeded in distilling purified rubber without decomposition by heating it in a high vacuum to the temperature of boiling water. This statement was based on the results of this experiment. However, the temperature of distillation was not that of boiling water, but $160^{\circ} \mathrm{C}$. On the basis of this

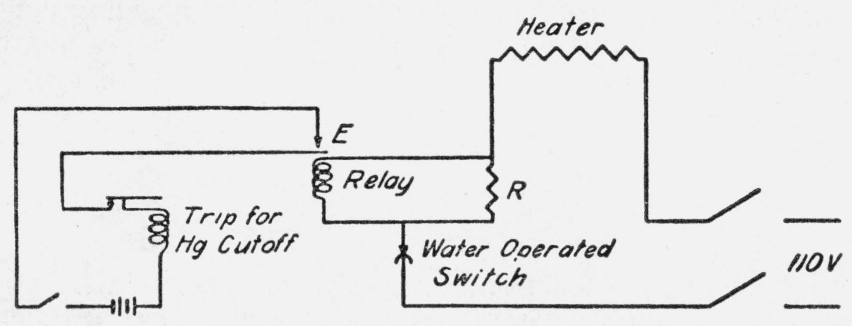

Figure 4.

statement, Lens [8] attempted a similar distillation with crude rubber. His experiments failed entirely, however, and probably the temperature of distillation was $100^{\circ} \mathrm{C}$ and consequently too low.

For the second experiment, solid carbon dioxide and acetone were used in the condenser, which was maintained at approximately $-78^{\circ} \mathrm{C}$. Distillation was conducted only during the day for a total operating period of about 250 hours. When the still was opened there was an odor of levulinic aldehyde, and when a portion of the undistilled rubber was placed in a hot solution of ammonium acetate, 
the vapors of the latter gave a positive pyrrol test with a pine shaving which had been moistened with hydrochloric acid. [9] Levulinic aldehyde is an oxidation product of rubber that responds to the pyrrol test. The thin layer of distillate was transparent, hard, and insoluble in carbon disulfide. There was about $5 \mathrm{mg}$ of distillate.

A third experiment was conducted with tap water in the condenser. The distillation was continuous over 140 days, and during most of the period the temperature of the tap water varied from $8^{\circ}$ to $10^{\circ} \mathrm{C}$. At the end of the experiment, the residue of undistilled rubber was clear, almost colorless, and recovered slowly when deformed. The material deposited on the condenser, amounting to not more than $20 \mathrm{mg}$, was visible without a lens. It had collected in droplets, was transparent, and was hard, and not extensible or plastic. There was a marked odor of levulinic aldehyde in the distillate and in the undistilled residue. The distillate was insoluble in ether, benzene, chloroform, ethyl acetate, alcohol, and acetone. Enough of it was scraped from the condenser for a determination of its iodine number by the Kemp-Wijs method [10], but with a dilute solution of iodine. Although the material was insoluble in carbon disulfide, it swelled sufficiently to permit penetration by the iodine solution. The end point was definite. A value of 328 was obtained. The iodine number of purified rubber, determined by the same procedure, was 370 . The degree of unsaturation of a cyclic rubber, which was made by incorporating sulfonic acids and heating to $140^{\circ} \mathrm{C}$, has been reported as 55 to 65 percent of that of the rubber hydrocarbon [11].

Marked oxidation had undoubtedly occurred during the second and third experiments. The original ethereal solution, though saturated with nitrogen before it was introduced into the still, was exposed to air during the process. It was hoped that any oxygen dissolved in the rubber as a result of this exposure would be removed at thelow pressure used, but apparently some was retained. Furthermore, cyclic rubber may have slowly formed at $160^{\circ} \mathrm{C}$, and may have distilled. In the second and third experiments, the marked difference in the physical characteristics of the distillate which had been maintained at $10^{\circ} \mathrm{C}$, and that of the undistilled rubber which had been heated to $160^{\circ} \mathrm{C}$, suggests this possibility. Rubber has a marked tendency to form cyclic compounds, and Kirchhof has shown that they are produced at $200^{\circ} \mathrm{C}$.

\section{REFERENCES}

[1] R. Pummerer, A. Andriessen, and W. Gündel, Ber. deut. chem. Ges. 62, 2628 (1929).

[2] K. H. Meyer and H. Mark, Ber. deut. chem. Ges. 61, 1945 (1928).

[3] H. Staudinger, Die hochmolecularen organischen Verbindungen (J. Springer, Berlin, 1932); H. Staudinger and E. O. Leupold, Ber. deut. chem. Ges. 6\%, 304 (1934).

[4] E. W. Washburn, BS J. Research 2, 476 (1929) RP45.

[5] E. O. Kraemer and J. D. Lansing, Rubber Age 37, 25 (1935).

[6] W. Harold Smith, Charles Proffer Saylor, and Henry J. Wing, BS J. Research 10, 479 (1933) RP544.

[7] BS Tech. News Bul. 161, p. 85 (Sept. 1930).

[8] J. Lens, Rec. Trav. Chim. 51, 972 (1932).

[9] G. Bruni and C. Pelizzola, India Rubber J. 63, 415 (1922).

[10] A. R. Kemp, Ind. Eng. Chem. 19, 531 (1927).

[11] H. L. Fisher and E. M. McColm, Ind. Eng. Chem. 19, 1329 (1927).

WASHINGTON, January 30, 1939. 